\title{
Letter from the Centre
}

For the past months, Itinerario would seem to have been in hiding; in fact we fell victims to reallocations of space. Or rather, our wordprocessing department did, and for one black moment at the beginning of this year, its candle was very nearly extinguished. By now, things are nearly back to normal, we hope. At the same time, we have new and better things in store for you and for ourselves.

You may have noticed that this edition and the last - the 1985-2 number devoted to Professor Meilink-Roelofsz's eightieth birtday - were printed professionally by Grafaria press of Leiden. Mrs. de Graaff, its owner, has helped us improve its appearance dramatically and you may notice we have shifted to a new page format, beginning with this issue. Needless to say, from this number henceforth, we hope to remain on schedule.

You will notice that it is our second special issue in succession, which is more a product of circumstance than design. It is devoted to papers presen $\bullet$ ed last year in New Delhi at the first in a series of conferences reflecting the Cambridge-Delhi-Leiden-Yogyakarta Project. This emerged from a meeting in 1981 between Professor H.L. Wesseling, of this university, and Prof. Dharma Kumar, of the Delhi School of Economics. In it they discussed the feasibility of an ongoing research project on the comparative study of India and Indonesia involving Indian, Indonesian, British and Dutch scholars. The following year Professor Wesseling converted it in a formal proposal, sent copies to the Delhi School, to the Cambridge Centre for South Asian Studies and to the Centre for Rural and Regional Studies of the Gadjah Mada University at Yogyakarta. The idea was well received by all three universities, whereupon a supporting grant was given by the Dutch Ministries of Education and of Foreign Affairs to bring the planners together. This took place in October, 1983.

The first fruit of the planning session has been a project for four conferences, one held (or to be held) at each participating institution. Of these, two have already taken place, each dealing with a certain theme and period. 
The first, in Delhi, dealt with 'India and Indonesia from the 1920s to the 1950s; the Origins of Planning'. Leiden played host to the second, 'The Heyday of Colonial Rule (1830s - 1914)', and the last two are still to come. They will deal with 'India and Indonesia in the 17 th and 18th Centuries' (at Yogyakarta) and 'General Reflections and Long Term Perspectives' (at Cambridge). You will notice that the idea is to start with recent situations in the developing countries and to work backwards through time in order to seek the roots of present-day problems. Or, in other words, the relation between colonialism and (under)development.

Herewith are the papers from the New Delhi conference, held in January, 1985. We hope you will like them.

The Editors 